\title{
Influence of Dietary Soy Phytoestrogens on Cytokine Production and Immunoglobulin in Ovariectomized Rats
}

\author{
Abeir Shalaby ${ }^{*}$, and Rania Abdel Rahman Elgawish ${ }^{2}$
}

\begin{abstract}
This study was designed to examine the relationship between soy phytoestrogens supplementation in ovariectomized rats and pro-inflammatory cytokines Interleukin 1 alpha (IL-1 $\alpha$ ), Interleukin 2 (IL-2), Interleukin 4 (IL-4) and immunoglobulin. Twenty four female rats were ovariectomized then divided equally into 3 groups; control group, was fed on casein based diet, low soy phytoestrogens group was fed a diet contained $7 \%$ soy and high soy phytoestrogens group received a diet of $26 \%$ soy for 28 days. At the end of experiment, rats were weighed then blood samples were collected on EDTA for total leukocyte count (TLC). Serum samples were taken for interleukins assay, lysozyme activity and immunoglobulin. Animals were sacrificed and thymus and spleen were weighed. The body weight gain was significantly declined in ovariectomized rats fed high soy diet at the first 3 weeks of the experiment. Rats fed high soy diet showed significant reduction in thymic weight compared to control ones. IL-1 $\alpha$ and IL-2 were significantly suppressed in rats fed high soy diet compared to control rats. However, IL-4 was significantly stimulated in rats fed high soy diet compared to control rats. Both $\operatorname{IgM}$ and $\operatorname{IgG}$ levels were significantly increased in rats fed high soy diet compared to control rats. There was a significant decrease in lysozyme activity in rats fed high soy diet compared to rats fed low soy diet. TLC was significantly increased in rats fed high and low soy diets. In conclusion, soy supplementation altered selected immunological parameters of ovariectomized female rats.
\end{abstract}

Keywords-Soy, ovariectomized rats, interleukins, immunoglobulin.

\section{INTRODUCTION}

I $\mathrm{N}$ recent years, researchers have tried to unravel the highly complex relationship between nutrition, immunology and cancer. A growing body of evidence suggests that nutrition and immune function are closely related. The cells of the immune system evolve from pluripotent hematopoietic stem cells found in the bone marrow. The immune cells are classified as either granulocytes or agranulocytes. The granulocytes include the basophils, mast cells, eosinophils, and neutrophils and the agranulocytes include the monocytes, natural killer (NK) cells, and lymphocytes. The lymphocytes

\footnotetext{
${ }^{1}$ Department of Biochemistry, Faculty of Veterinary Medicine, Suez Canal University, Ismailia, Egypt

${ }^{2}$ Department of Forensic Medicine and Toxicology, Faculty of Veterinary Medicine, Suez Canal University, Ismailia, Egypt

*Corresponding author at: Department of Biochemistry, Faculty of Veterinary Medicine, Suez Canal University, Ismailia, Egypt
}

are further divided into the B lymphocytes and $\mathrm{T}$ lymphocytes [1]. Natural killer (NK) cells which make up about $15 \%$ of circulating lymphocytes can be also distinguished by their unique cell surface markers. Resting NK cells also express a portion of certain cytokine receptors such as the interleukin-2 receptor [2]. In turn, cytokines represent a group of molecules, which are produced by $\mathrm{T}$ cells, B cells and/or macrophages to serve as mediators between the different types of immune cells. For example, binding with IL-2 leads to stimulation and subsequent activation of NK cells and T cells [3]. Additionally, immunoglobulin $\mathrm{M}$ ( $\operatorname{IgM})$ is the first antibody to respond to foreign antigen. While, immunoglobulin $\mathrm{G}$ (IgG) accounts for $70-75 \%$ of the immunoglobulin in human serum. It is the major antibody of the secondary immune response [1].

Soybeans are rich sources of the phytoestrogens genistein and daidzein (belong to isoflavones), which continue to be investigated for their potential in reducing the risk for cardiovascular diseases, osteoporosis and certain types of cancer [4]. Soy phytoestrogens may affect immune functions as weak estrogen agonists or antagonists. Both genistein and daidzein possess weak estrogenic activity due to their structural similarity to 17ß-estradiol [5]. Since the immune system is, in part, regulated by steroid hormones [6], soy phytoestrogens may influence immunocompetence via estrogen-receptor mediated mechanisms. In addition, soy phytoestrogens possess a variety of immune characteristics including antioxidant, anti-proliferative and antiinflammatory properties.

Despite the hypothesized beneficial effects of phytoestrogen, there are concerns about the potential side effects of this compound on immune system in animals. Therefore, this study was designed to examine the relationship between soy phytoestrogens supplementation in ovariectomized rats and specific aspects of immunity as proinflammatory cytokines (IL-1 $\alpha$ ), preferential production of Th1 type of cytokines (IL-2), Th2 cytokine regulatory pathway (IL-4) and immunoglobulin. 


\section{MATERIALS AND METHODS}

\section{A. Animals and Ovariectomy}

Twenty-four adult female Albino rats weighing approximately 100-110 g were purchased from Lab. Animal House, Faculty of Veterinary Medicine, Suez Canal University. They were housed under standard laboratory conditions and kept at room temperature $\left(28 \pm 2{ }^{\circ} \mathrm{C}\right)$ with free access to casein based diet (soy free) and water. Experiment was carried out under Animal Care and Use Protocols Procedures approved by Faculty of Veterinary Medicine, Suez Canal University Committee, Egypt.

Female rats were ovariectomized (OVX), 2 week after arrival under effect of diethyl ether inhalation anesthesia [7]. Rats were given amoxicillin $10 \mathrm{mg} / \mathrm{kg}$ orally for 5 successive days after ovariectomy as well as casein based diet and water ad libitum and maintained on $12 \mathrm{~h}$ day and $12 \mathrm{~h}$ night cycle.

\section{B. Experimental Groups}

Twenty days after ovariectomy, the OVX female rats were divided randomly into three groups; control group $(n=8)$ was fed on casein based diet (soy free diet), low soy phytoestrogens group $(n=8)$ was fed a diet contained $7 \%$ soy and high soy phytoestrogens group $(\mathrm{n}=8)$ received a diet of $26 \%$ soy for 28 days. All diets were formulated according to Tag et al. [8] to fulfill all the nutritional requirements of adult rats according to NRC [9]. Food consumption for all rats in each group/week was determined. Body weight gain ( $\mathrm{g} /$ week) was obtained by determination of difference between two successive body weights, for each rat at one-week interval.

\section{C.Blood and Tissue Samples}

At the end of experiment (28 days of treatment), the rats were weighed then blood samples were collected from retroorbital venous plexus on EDTA tubes for total leukocyte count. Other blood samples were taken in plain tubes and were kept for $15 \mathrm{~min}$. at room temperature then centrifuged at $3000 \mathrm{rpm}$ for $20 \mathrm{~min}$. The serum was stored at $-20{ }^{\circ} \mathrm{C}$ till interleukins assay, immunoglobulin and lysozyme assay. Animals were then sacrificed. Thymus and spleen were dissected and weighed. Their relative weights were calculated in relation to body weight as follow,

Relative thymic weight $=$ [thymus weight $(\mathrm{g}) /$ body weight (g)] X 100

Relative splenic weight $=[$ spleen weight $(\mathrm{g}) /$ body weight (g)] X 100

\section{D.Interleukins Assay}

Serum IL-1 $\alpha$ was analyzed by ELISA using solid phase sandwich ELISA obtained from Biological Laboratories Co. Ltd. (Catalog No. 27193, USA). IL-2 was measured using specific rat ELISA kits (IB49713, USA). IL-4 was measured using specific rat ELISA kit (IB49709, USA). All parameters were determined according to kit manufacturer instruction.

\section{E. Immunoglobulin Assay}

IgM and IgG assays were performed by Abcam's rat ELISA Kit (KEMET Medical, Egypt). Abcam's rat ELISA kit is an in vitro enzyme-linked immunosorbent assay for the quantitative measurement of $\operatorname{IgM}$ and IgG. In this assay the IgM present in samples reacts with the anti-IgM antibodies, which have been adsorbed to the surface of polystyrene microtiter wells. After the removal of unbound proteins by washing, anti-IgM antibodies conjugated with horseradish peroxidase (HRP) are added. These enzyme-labeled antibodies form complexes with the previously bound IgM. Following another washing step, the enzyme bound to the immunosorbent is assayed. The absorbance, at $450 \mathrm{~nm}$, is a measure of the concentration of IgM in the test sample.

\section{F. Lysozyme Enzyme Assay}

Lysozyme activity was measured by agarose gel cell lysis assay according to the method described by Schultz [10]. Briefly, lysoplates were prepared by dissolving $0.01 \%$ agarose in $0.0067 \mathrm{M}$ PBS $(\mathrm{pH} 6.3)$ at $100{ }^{\circ} \mathrm{C}$, when agarose temperature reached $60-70{ }^{\circ} \mathrm{C}, 500 \mathrm{mg}$ of uniform suspension of Micrococcus lysodeikticus in $5 \mathrm{ml}$ saline was added to one liter of agarose and mixed well, then the plates were poured into wells. To which, exactly $25 \mu$ of each of the serum samples and standard lysozyme solutions were put in each poured well. They were incubated at $28-30{ }^{\circ} \mathrm{C}$ for 12-18 $\mathrm{h}$ and the clear zone ring diameters were measured. The diameters of clear zones were plotted against the standards for obtaining lysozyme concentration in the samples.

\section{G.Total Leukocyte Counts (TLC)}

Blood samples were collected from retro-orbital venous plexus of ovariectomized female rats at the end of experimental period on EDTA containing tubes and placed immediately on ice for TLC. Leukocytes were counted by Neubauer's improved haemocytometer using Turkey's solution. The number of leukocytes was calculated according to Feldman et al. [11].

\section{H. Statistical Analysis}

All values were expressed as mean \pm standard error of the mean. One-way analysis of variance was used for analyzing the differences among groups. Inter-group comparisons were made by Tukey's test. $P$ value of $<0.05$ was considered to indicate significance. All the analyses were done using Graph Pad Prism (Version 5.01, Graph Pad software, San Diego, USA).

\section{RESULTS}

\section{A. Body Weight Gain and Food Intake}

The body weight gain was significantly declined in ovariectomized rats fed high soy diet at the first three weeks of the experiment. However, no significant difference was detected in the body weight gain at the end of the experiment 
(Fig. 1). The food intake was similar in control and treated female rats without any significant differences.

\section{B. Spleen and Thymus Weights}

Rats fed high soy diet showed significant reduction in thymic weight compared to that of control ones. While, there was no difference in splenic weight between control and treated rats (Fig. 2).

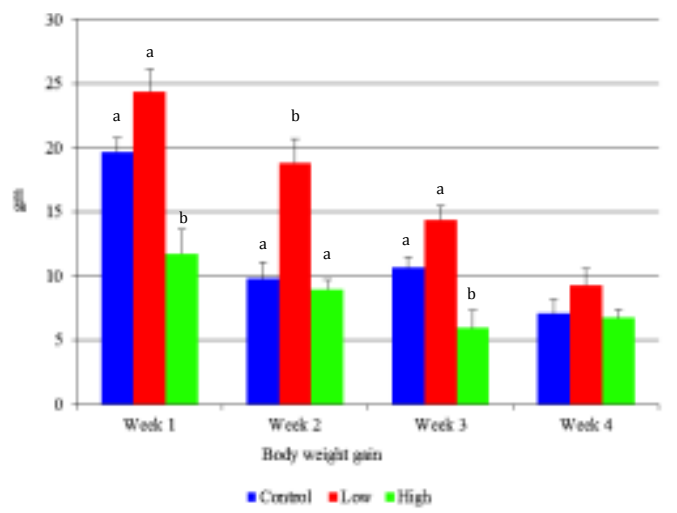

Fig. 1: Body weight gain at different weeks in ovariectomized rats fed low and

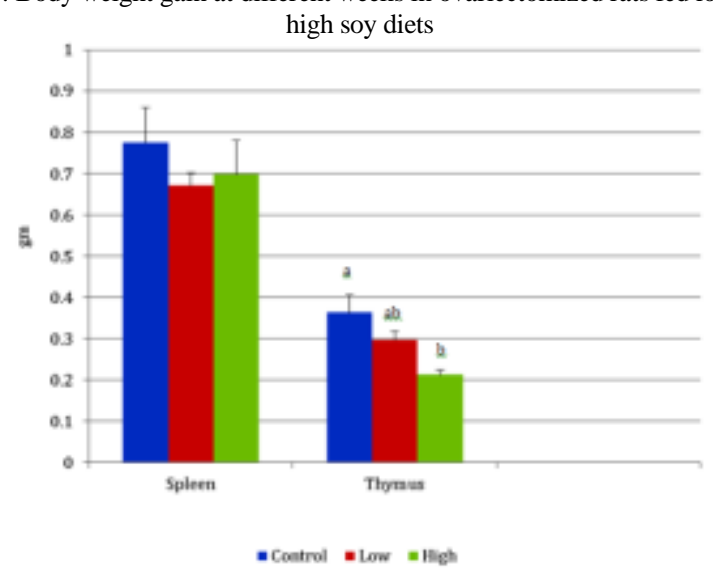

Fig. 2: Spleen and thymus weights in ovariectomized rats fed low and high soy diets

\section{Interleukin Assay}

IL-1 $\alpha$ and IL-2 were significantly suppressed in rats fed high soy diet compared to that in control rats. However, IL-4 was significantly stimulated in rats fed high soy diet compared to that in control rats (Table 1).

\section{D.Immunoglobulin}

Both $\operatorname{IgM}$ and $\operatorname{IgG}$ were significantly increased in rats fed high soy diet compared to that in control rats (Table 1).

\section{E. Lysozyme Activity Assay and TLC}

There was a significant decrease in lysozyme activity in rats fed high soy diet compared to rats fed low soy diet. TLC was significantly increased in rats fed high and low soy diet compared to that in control rats (Table 1).
TABLE I: EFFECTS OF SOY SUPPLEMENTATION ON INTERLEUKINS, IMMUNOGLOBULIN, LYSOZYME ACTIVITY AND TOTAL LEUCOCYTE IN CONTROL, LOW AND HIGH SOY DIET FED RATS.

\begin{tabular}{|c|c|c|c|c|}
\hline & Cuend & 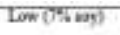 & 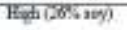 & $P=$ \\
\hline The pant & $860=023^{\circ}$ & 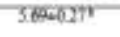 & $335=0152$ & $0 \% 01$ \\
\hline II. $2(j e=0)$ & o.tsesast. & $07 \pi=0.035$ & 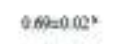 & 00007 \\
\hline It. $4(\pi x=b$ & 33034241. & 6e.214:414 & nsesesso: & 00001 \\
\hline $\lg 0(x g=1)$ & $s 02=037^{*}$ & $50.460032^{\circ}$ & $12010064 \%$ & 60001 \\
\hline 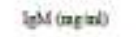 & $0.24=001$. & 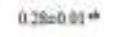 & estabator & 0002 \\
\hline 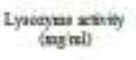 & $218+1040$ & $3214=9.44$ & $2773+148$ & 0.63 \\
\hline TLCElotial & $10023=54 ! 4^{4}$ & $19008=6654^{\circ}$ & $13912+578.3^{\circ}$ & 0.0001 \\
\hline
\end{tabular}

Different superscripts within the same row indicated significant differences at $P<$ 0.05

\section{DISCUSSION}

Data from animal studies have indicated that phytoestrogens may either enhance or suppress immunocompetence depending on their concentration, the target tissue and a number of other factors. The mechanisms underlying these effects are not fully understood, and further investigations are needed to explore the detailed molecular mechanism regulated by phytoestrogens. Genistein significantly reduced inflammatory mediators, such as IL-1 $\beta$, IL- 6 and IL-8 production, in TNF- $\alpha$-activated MH7A cells in vitro [12]. The anti-inflammatory properties of genistein are mediated by the interruption of the ROS/Akt/NF- $\kappa$ B signaling pathway in MH7A cells. These signaling led to a marked decrease of TNF- $\alpha$-induced pro-inflammatory cytokine production [12].

In the present study, the body weight gain was significantly declined in ovariectomized rats fed high soy phytoestrogens diet at the first three weeks of the experiment. However, no significant difference was detected in the body weight gain at the end of the experiment. Additionally, there were no significant changes in food intake in control and treated rats. The decrease in body weight gain in spite of absence of change in food consumption may be due to loss of large amount of ingested food energy during the increased locomotor activity [13], as observed in the rats of the current study. This decrease suggested that estrogenic hormone action of phytoestrogens was beneficial to body fat regulation and influenced the hypothalamic neuropeptide levels $[14,15]$.

In the preset study, rats fed high soy diet showed significant reduction in thymic weight compared to that of control ones. Genistein (5 mg/d for 21 d) intravenously injected into ovariectomized female mice resulted in an $80 \%$ reduction of thymic weight, while genistein injection at 2 $\mathrm{mg} / \mathrm{d}$ for only $7 \mathrm{~d}$ led to a $70 \%$ decrease in thymic weight [16]. Genistein reduced the numbers of peripheral CD4+ and $\mathrm{CD} 8+\mathrm{T}$ cells and this reduction might come from thymic atrophy [17].

In the present study, there was a stimulation of IL-4 and suppression of IL-1 $\alpha$ and IL-2 levels in ovariectomized rats fed high soy diet. This may indicate that phytoestrogen may inhibit and/or stimulate specific immune cells. Possible link 
between high levels of soy consumption and immune impairments was contradictory. There were previous reports indicated that $\mathrm{T}$ cell function and immunoglobulin were decreased in infants fed soy formula compared with cow milk formula fed controls [18, 19]. Further evidence implies that soy phytoestrogens may suppress immune function when rats fed diets containing high doses of soy phytoestrogens as immunosuppressive agent to delay rejection of rat cardiac allografts [2]. In contrast, two reports did not confirm the extensive immune abnormalities described previously and reported that a number of parameters related to immune cell populations were within the normal range in soy-fed infants [20, 21]. Phytoestrogen and some of their metabolites may affect allergic responses via the enhancement of IL-4 production in $\mathrm{T}$ cells [22]. The functions of $\mathrm{T}$ cells and $\mathrm{NK}$ cells were altered after oral exposure to genistein at physiologically relevant concentrations in experimental animals. Specifically, exposure to genistein in adult female mice for 28 days by gavage increased the activities of cytotoxic T cells and NK cells [23].

Both $\operatorname{IgM}$ and $\operatorname{IgG}$ were significantly increased in rats fed high soy diet compared to that in control rats. Although genistein increased $\operatorname{IgM}$ at the dose of $6 \mathrm{mg} / \mathrm{kg}$ in adult female B6C3F1 mice, no effect was observed in the high dose group. Furthermore, exposure to genistein had no effect on IgG response [23]. Oral administration of daidzein to Swiss mice increased the thymic mass and number of lymphocytes in blood and resulted in elevated antigen-specific IgM [24]. In the current study, it was clear that soy phytoestrogens stimulated the B1 cell response which is immunocompetent and suppressed $\mathrm{T}$ cell response. This confirmed the estrogenic effect of soy as estrogen is well known to stimulate IgM from B1 cells by direct way through ER- $\beta$ signaling pathway [25].

In the present work, the increase in IL-4, IgG and $\mathrm{IgM}$ as well as the decrease in pro-inflammatory cytokines IL- $1 \alpha$ and IL-2 implies the favorable effect of soy phytoestrogens on Immunity as they improved general humeral immune response and prevented autoimmunity as IL-4 stimulated signaling array in B cells [26]. Moreover, inhibition of IL-2 production led to the inhibition of Th1 and enhancement of Th2 cytokine synthesis in CD4+ T cells [27].

There was a significant decrease in lysozyme activity in rats fed high soy diet compared to rats fed low soy diet. Lysozyme is a ubiquitous enzyme present in biological secretions and leukocyte. Lysozyme hydrolyzes $\beta-(1-4)-$ glucosidic linkages between $\mathrm{N}$-acetylmuramic acid and $\mathrm{N}$ acetyl-D-glucosamine residues present in the mucopolysaccharide cell wall of a variety of microorganisms. It might reflect the effect of soy on phagocytic ability of the macrophage in ovariectomized rats. In the preset study, TLC was significantly increased in rats fed high and low soy diet compared to that in control rats. This might highlight the role of estrogen in down regulating the expression of adhesion and chemokine molecules in response to inflammation [28]. Researchers have also reported that estrogen treatment altered the recruitment and adhesion of leukocytes to the endothelium, which was induced by inflammation [29]. The result of TLC and lysozyme enzyme activity supported the anti-inflammatory effect of soy phytoestrogens and their promising rule in prevention of autoimmune diseases.

\section{CONCLUSION}

Data from this study revealed that 28 days of soy phytoestrogens supplementation altered selected immunological parameters in ovariectomized rats. This is important information proved the ability of the soy phytoestrogens to modulate immunoglobulin and cytokine production in ovariectomized female rats by favoring the humeral immunity and lowering auto-immunity. However, further studies documenting the long-term effect of soy supplementation on immunity are warranted.

\section{ACKNOWLEDGMENT}

The authors thank Dr. Mahmoud Fathy and Dr. Mohamed Abdalla, Surgery Department, Faculty of Veterinary Medicine, Suez Canal University, Ismailia, Egypt for their help and cooperation during ovariectomy.

\section{REFERENCES}

[1] D. Male, J. Brostoff, D. Roth, and I. Roitt, Components of the immune system in: Immunology, 7 th ed. Elsevier, UK., 2006, pp. 3-19.

[2] T. P. O’Connor, D. A. Liesen, P. C. Mann, L. Rolando, and W. J. Banz, “A high isoflavone soy protein diet and intravenous genistein delay rejection of rat cardiac allografts,' Journal of Nutrition, 132(8), pp. 2283-2287, 2002.

[3] P. Alexandersen, A. Toussaint, C. Christiansen, J. P. Devogelaer, C. Roux, J. Fechtenbaum, C. Gennari, J. Y. Reginster, and I. M. E. F. Study, "Ipriflavone in the treatment of postmenopausal Osteoporosis," Journal of American Medical Association, vol. 285(11), pp. 1482-1488, 2001. http://dx.doi.org/10.1001/jama.285.11.1482

[4] C. R. Sirtori, and M. R. Lovati,"Soy proteins and cardiovascular disease," Current Atherosclerosis Report, vol. 3(1), pp. 47-53, 2001. http://dx.doi.org/10.1007/s11883-001-0010-2

[5] M. J. Messina, V. Persky, K. D. Setchell, and S. Barnes,"Soy intake and cancer risk: A review of the in vitro and in vivo data," Nutrition Cancer, vol. 21, pp. 113-131, 1994. http://dx.doi.org/10.1080/01635589409514310

[6] W. Wang, C. Higuchi, and R. Zhang, "Individual and combinatory effects of soy phytoestrogens on the in vitro potentiation of lymphocyte activation,'” Nutrition Cancer, vol. 29(1), pp. 29-34, 1997. http://dx.doi.org/10.1080/01635589709514598

[7] D. K. Khajuria, R. Razdan, D. and R. Mahapatra, "Description of a new method of ovariectomy in female rats,', Rev. Bras. Reumatol., vol. 52(3), pp. 462-467, 2012.

[8] H. M. Tag, H. M. Tantawy, and R. M. Ghoneim, "Effect of soy isoflavones on some immunological parameters in ovariectomized female rats,' Egypt Acad. Journal of Biol. Sci., vol. 6(1), pp. 101-113, 2014.

[9] NRC, Nutrient Requirements of Laboratory Animals, 4 th revised ed. National Academic Paris, Washington D. C., 1995.

[10] A. Schultz, Methods in Clinical Chemistry, The C.V. Mosby Co. St. Louis, 1987, pp. 742-746.

[11] B. F. Feldman, J. G. Zinki, and V. C. Jain, Schalm's Veterinary Hematology, 5 th ed. Lippincot Wilkins, Canada, 2000, pp. 1145-1146.

[12] J. Li , J. Li , Y. Yue, Y. Hu, W. Cheng, R. Liu, X. Pan, and P. Zhang, "Genistein suppresses tumor necrosis factor $\alpha$-induced inflammation via modulating reactive oxygen species/Akt/nuclear factor $\kappa \mathrm{B}$ and adenosine monophosphate-activated protein kinase signal pathways in human synoviocyte MH7A cells,' Drug Design, Development and Therapy, vol. 8, pp. 315-323, 2014 http://dx.doi.org/10.2147/DDDT.S52354

[13] K. S. Weber, K. D. Setchell, D. M. Stocco, and E. D. Lephart,"Dietary soyphytoestrogens decrease testosterone levels and prostate weight without altering $\mathrm{LH}$, prostate 5-alpha reductase or testicular steroidogenic acute 
regulatory peptide levels in adult male Sprague-Dawley rats," Journal of Endocrinology, vol. 170(3), pp. 591-599, 2001.

http://dx.doi.org/10.1677/joe.0.1700591

[14] K. Szkudelska, L. Nogowski, and T. Szkudelski, "'Genistein affects lipogenesis and lipolysis in isolated rat adipocytes," Journal of Steroid Biochem. Mol. Biol., vol. 75, pp. 265-271, 2000. http://dx.doi.org/10.1016/S0960-0760(00)00172-2

[15] A. Naaz, S. Yellayi, M. A. Zakroczymski, D. Bunick, D. R. Doerge, D. B. Lubahn, W. G. Helferich, and P. S. Cooke," The soy isoflavone genistein decreases adipose deposition in mice," Endocrinology, vol. 144, pp. 3315$3320,2003$. http://dx.doi.org/10.1210/en.2003-0076

[16] S. Yellayi, A. Naaz, S. Tomomi, M. Szecwczykowski, P Cooke,"'Genistein causes thymic atrophy and changes in lymphocyte subpopulations: potential health implications?," FASEB Journal, vol. 15(4), pp. A498.10, 2001.

[17] S. Yellayi, A, Naaz, M. A. Szewczykowski, T. Sato, J. A. Woods, J. Chang, M. Segre, C. D. Allred, W. G. Helferich, and P. S. Cooke, "The phytoestrogen genistein induces thymic and immune changes : a human health concern," Proc. Natl. Acad. Sci. USA, vol. 99, pp. 7616-7621, 2002. http://dx.doi.org/10.1073/pnas.102650199

[18] G. Zoppi, G. Zamboni, N. Bassani, and G. Vazzoler,"'Gammaglobulin level and soy-protein intake in early infancy," European Journal of Pediatrics, vol. 131, pp. 61-69, 1979. http://dx.doi.org/10.1007/BF00442786

[19] G. Zoppi, F. Gerosa , A. Pezzini, N. Bassani, P. Rizzotti, P. Bellini, G. Todeschini , G. Zamboni, G. Vazzoler, and G. Tridente, "Immunocompetence and dietary protein intake in early infancy," Journal of Pediatric Gastroenterology Nutrition, vol. 1, pp. 175-182, 1982. http://dx.doi.org/10.1097/00005176-198201020-00005

[20] C. T. Cordle, T. R. Winship, J. P. Schaller, D. J. Thomas, R. H. Buck, K. M. Ostrom, J. R. Jacobs, M. M. Blatter, S. Cho, W. M. Gooch, and L. K. Pickering, "Immune status of infants fed soy-based formulas with or without added nucleotides for 1 year. Part 2: immune cell populations," Journal of Pediatric Gastroenterology Nutrition, vol. 34, pp. 137-144, 2002.

http://dx.doi.org/10.1097/00005176-200202000-00008 http://dx.doi.org/10.1097/00005176-200202000-00007

[21] K. M. Ostrom, C. T. Cordle, J. P. Schaller, T. R. Winship, D. J, Thomas, J. R. Jacobs, M. M. Blatter, S. Cho, W. M. Gooch, D. M. Granoff, H. Faden, and L. K. Pickering, "Immune status of infants fed soy-based formulas with or without added nucleotides for 1 year. Part 1: vaccine responses and morbidity,' J Pediatric Gastroenterology Nutrition, vol. 34, pp. 137-144, 2002. http://dx.doi.org/10.1097/00005176-200202000-00007

[22] T. Sakai, and M. Kogiso, "Soy phytoestrogens and immunity," Journal of Medical Investigation, vol. 55, pp. 167-173, 2008. http://dx.doi.org/10.2152/jmi.55.167

[23] T. L. Guo, J. A. McCay, L. X. Zhang, R. D. Brown, L. You, N. K. Karrow, D. R. Germolec, and K. L. White KL, "Genistein modulates immune responses and increases host resistance to B16F10 tumor in adult female B6C3F1 mice," Journal of Nutrition, vol. 131, pp. 3251-3258, 2001.

[24] R. Zhang, Y. Li, and W. Wang, "Enhancement of immune function in mice fed high doses of soy daidzein," Nutr. Cancer, vol. 29 (1), pp. 24-28, 1997. http://dx.doi.org/10.1080/01635589709514597

[25] H. Yurino H, S. Ishikawa, T. Sato, K. Akadegawa, T. Ito, S. Ueha, H. Inadera, K. Matsushima, "Endocrine disruptors (environmental estrogens) enhance autoantibody production by B1 cells," Toxicol. Sci., vol. 81(1), pp. 139-147, 2004. http://dx.doi.org/10.1093/toxsci/kfh179

[26] S. Reyes-Cerpa, F. E. Reyes-Lopez, D. Toro-Ascuy, J. Ibanez, K. Maisey, A. M. Sandino, M. Imarai, "IPNV modulation of pro and antiinflammatory cytokine expression in Atlantic salmon might help the establishment of infection and persistence,' Fish Shellfish Immunol., vol. 32(2), pp. 291-300, 2012. http://dx.doi.org/10.1016/j.fsi.2011.11.018

[27] Y. Kang, J. Song, K. M. Kim, Y. K. Choe, S. Y. Hwang, T. S. Kim, "Curcumin inhibits Th1 cytokine profile in CD4+ T cells by suppressing interleukin-12 production in macrophages," British Journal of Pharmacology, vol. 128(2), pp. 380-384, 1999. http://dx.doi.org/10.1038/sj.bjp.0702803
[28] C. N. Ugochukwu, P. E. Ebong, and E. U. Eyong, "Biochemical implication of long term administration of Halofantrine Hydrochloride (Halfan) on estradiol level of female wistar rats," Pakistan Journal of Nutrition, vol. 7(2), pp. 227-230, 2008. http://dx.doi.org/10.3923/pjn.2008.227.230

[29] O. Nilsson, "Modulation of the inflammatory response by estrogens with focus on the endothelium and its interactions with leukocytes," Inflammation Research, vol. 56 (7), pp. 269-273, 2007. http://dx.doi.org/10.1007/s00011-007-6198-z 